\title{
Evaluation of in vitro anti-Trypanosoma cruzi activity of medications benznidazole, amiodarone hydrochloride, and their combination
}

\author{
Angela Maria Lourenço ${ }^{[1]}$, Cristiane Castro Faccini ${ }^{[1]}$, Cristiane Aparecida de Jesus Costa ${ }^{[1]}$, \\ Gabrielle Balestrin Mendes ${ }^{[1]}$ and Abilio Augusto Fragata Filho ${ }^{[1]}$
}

[1]. Laboratório de Doença de Chagas, Instituto de Cardiologia Dante Pazzanese, São Paulo, SP, Brasil.

\begin{abstract}
Introduction: Approximately seven to eight million people worldwide have Chagas disease. In Brazil, benznidazole is the most commonly used active drug against Trypanosoma cruzi; however, its efficacy is limited, and side effects are frequent. Recent studies suggest that amiodarone may be beneficial in the treatment of this disease, by exerting anti-T. cruzi action. This study evaluated changes in $T$. cruzi cell count in in vitro cultures subjected to different doses of benznidazole, amiodarone, and their combination. Methods: T. cruzi (Y strain) cultures containing approximately 100,000 cells were treated with either 100mg, $50 \mathrm{mg}, 25 \mathrm{mg}, 12.5 \mathrm{mg}$, or $10 \mathrm{mg}$ of benznidazole, amiodarone, or their combination. On the 4th day, cell count was compared to the baseline data. Results: On the 4th day, no parasites were observed in any of the treated cultures. Conclusions: Benznidazole and amiodarone were equally effective in eliminating $T$. cruzi in culture. The combination of the two drugs was also equally effective, but our data cannot demonstrate synergism, as similar results were obtained when the drugs were tested individually or in combination. It is suggested that this study be repeated with other $T$. cruzi strains to determine whether similar results can be obtained again.
\end{abstract}

Keywords: Chagas disease. Trypanosoma cruzi. Trypanocidal activity. Benznidazole. Amiodarone hydrochloride.

\section{INTRODUCTION}

Chagas disease was described by Carlos Chagas in 1909. Its etiologic agent is the flagellate protozoan Trypanosoma cruzi ${ }^{1}$. T. cruzi infection in humans is one of the major endemic diseases in Latin America ${ }^{2}$. It is estimated that approximately seven to eight million people worldwide are infected ${ }^{3}$. Vector transmission occurs through the penetration of metacyclic trypomastigotes, present in the feces and urine of insects, through damaged skin or through healthy mucosa ${ }^{2}$. In Brazil, the principal method of transmission is the oral route, which is responsible for increased morbidity and mortality and is becoming one of the most common modes of transmission from the public health perspective ${ }^{4}$. According to the Brazilian Consensus of Chagas Disease, trypomastigote, epimastigote, and perhaps amastigote forms of $T$. cruzi may be transmitted orally ${ }^{5}$. Transmission can also occur through the transfusion of infected blood, from mother to fetus, through organ transplantation, or through laboratory accidents ${ }^{3}$. Many inhabitants of Latin

Corresponding author: $\mathrm{Dr}^{\mathrm{a}}$ Angela Maria Lourenço.

e-mail: angela.lourenco@idpc.org.br

Received 30 August 2017

Accepted 2 January 2018
America have migrated to other continents, carrying this disease and transmitting it, mainly through blood transfusions and organ transplantation, to the inhabitants of non-endemic countries that do not have triatomine vectors. Chagas disease is therefore present in North America, Europe, Asia, and Oceania, making it a worldwide public health problem ${ }^{3,6}$.

The following developmental forms of Trypanosoma have been defined: epimastigote (found in axenic culture and in the digestive tract of the insect vector), trypomastigote (found in the insect vector, in cultured cells, and in the blood and intercellular space of the vertebrate host), and amastigote (found within vertebrate host cells or in cell cultures). T. cruzi can utilize a range of transmission mechanisms in the vertebrate host, and trypomastigotes are able to penetrate any type of cell (except neutrophils and eosinophils) in order to complete their life cycle. After penetration into the host cell, T. cruzi differentiates into the amastigote form and initiates the intracellular binary division process. The amastigotes transform into trypomastigotes, breaking open the host cell and moving into the bloodstream, spreading to penetrate cells of different organs, and then repeating the cycle ${ }^{7-9}$. In humans, the acute phase of the disease is characterized by intense parasitaemia and inflammation, but with low clinical expression and mortality. This phase lasts for approximately 8 to 10 weeks and is followed by a progressive decrease in the number of parasites 
in peripheral blood and initiation of the fibrotic process: a characteristic of the chronic phase ${ }^{2,10}$. When the insect feeds on human or contaminated animal blood, the circulating form of $T$. cruzi develops in its gut. A triatomine becomes infective 20 days after feeding with blood containing $T$. cruzi and can remain as such for its entire lifespan (approximately one year) ${ }^{8}$.

The disease may have different clinical presentations in humans, varying from region to region. Different strains of the parasite are found in nature, circulating between man, vectors, domestic animals, and wild reservoirs. These strains behave differently with regards to parasitaemia curves, interaction with host cells, and immune response ${ }^{7,9}$.

Nifurtimox and benznidazole are the only active drugs against $T$. cruzi; however, they have limited efficacy and cause frequent side effects ${ }^{9,11}$.

Amiodarone (a Class III antiarrhythmic drug) is the most widely used drug for the treatment of patients with Chagas disease and cardiac arrhythmia. Its antifungal and antiprotozoal actions have been recently identified ${ }^{12}$. Amiodarone contains active components that target $T$. cruzi, both in vitro and in experimental animals. It acts through homeostatic disruption of $\mathrm{Ca}^{2+}$ and blocks oxidosqualene cyclase activity in T. cruzi, causing ultrastructural damage ${ }^{13}$ and also blocking the biosynthesis of protozoan ergosterol ${ }^{14}$. Adesse et al. treated $T$. cruzi-infected cardiac myocytes with various concentrations of amiodarone and observed a different effect on the growth of the intracellular amastigote form of T. cruzi. They observed mitochondrial swelling and disorganization of reservosomes and the kinetoplast, as well as inhibition of the differentiation of amastigotes into trypomastigotes ${ }^{14}$. In a study using dronedarone (an amiodarone derivative), Benaim et al. showed that this new drug has the same effect on $T$. cruzi, using $50 \%$ of the concentration of amiodarone and observing the same mechanisms ${ }^{15}$. In a study using electron microscopy, Veiga-Santos et al. showed the synergic action of amiodarone and posaconazole (a potent antifungal drug) against T. cruzi, observing mechanisms that included wrinkling of the protozoan surface, swelling of the mitochondria, shedding of plasma membrane vesicles, alterations in the kinetoplast, disorganization of the Golgi complex, accumulation of lipid inclusion in the cytoplasm, and the formation of autophagic vacuoles ${ }^{16}$.

Our study evaluates the ability of amiodarone hydrochloride (amiodarone), benznidazole (BZ), and a combination of the two, to prevent the proliferation and/or to eliminate $T$. cruzi (Y strain) in vitro, at doses of $100 \mathrm{mg}, 50 \mathrm{mg}, 25 \mathrm{mg}, 12.5 \mathrm{mg}$, and $10 \mathrm{mg} / 100,000$ parasites.

\section{METHODS}

\section{Parasites}

The trypomastigote form of $T$. cruzi $\mathrm{Y}$ strain was obtained from in vivo cultures and maintained in the laboratory by successive passages in Swiss and A/Snell mice, weighing on average $23 \mathrm{~g}$ each. Mice were each inoculated with approximately $100,000 T$. cruzi cells. On the $8^{\text {th }}$ day after inoculation (at the peak of parasitaemia), the mice were euthanized, and blood was obtained by cardiac puncture. The plasma was separated. The red blood cell concentrate that is routinely neglected was used for the in vitro proliferation of $T$. cruzi. The entire procedure was performed in a completely sterile environment, using laminar flow and autoclaved materials, as per standard operating procedures.

\section{Proliferation in vitro}

The trypomastigote form of the parasite was cultivated in three test tubes, each containing $5 \mathrm{~mL}$ of liver infusion tryptose [(LIT), suitable for the cultivation of $T$. cruzi $\left.^{17}\right]$ medium supplemented with $10 \%$ inactivated fetal bovine serum; each tube received $1 \mathrm{~mL}$ of red blood cell concentrate, and was maintained in a growth chamber at $28^{\circ} \mathrm{C}$. Fresh preparations were examined after 10 days between a slide and coverslip $(22 \times 22 \mathrm{~mm})$ through an optical microscope, according to a previously described blood culture method ${ }^{18}$. After this period, $1 \mathrm{~mL}$ of the culture was transferred under laminar flow to another tube containing $5 \mathrm{~mL}$ LIT medium. After four days in a growth chamber maintained at $28^{\circ} \mathrm{C}$, the material was observed between a slide and coverslip, and parasite growth was determined by counting cells using a Neubauer hemocytometer, chosen for the study tubes with 100,000 T. cruzi cells per milliliter. On the $14^{\text {th }}$ day, almost all trypomastigotes had differentiated into epimastigotes. Epimastigotes, were used in this study because according to the Brazilian Consensus, this form may also be infective ${ }^{5}$. BZ [obtained from the Pharmaceutical Laboratory of the State of Pernambuco (LAFEPE)] was used as the gold standard in comparison with amiodarone (obtained from Libbs Laboratory). The commercial presentation of the two drugs was used as this is how patients are medicated, and because there are no data available on the trypanosomicidal action of the excipients.

The BZ and amiodarone tablets were macerated, weighed on a precision scale, and homogenized, together with $1 \mathrm{~mL}$ of complete LIT culture medium. The tablets were then added to test tubes containing $5 \mathrm{~mL}$ of the parasite solution, at the following doses:

- BZ: $100 \mathrm{mg}, 50 \mathrm{mg}, 25 \mathrm{mg}, 12.5 \mathrm{mg}$, and $10 \mathrm{mg}$.

- Amiodarone: $100 \mathrm{mg}, 50 \mathrm{mg}, 25 \mathrm{mg}, 12.5 \mathrm{mg}$, and $10 \mathrm{mg}$.

This procedure was performed twice for each dose of medication. In all procedures, two control tubes were prepared, without the addition of the drugs: all tubes were maintained at $28^{\circ} \mathrm{C}$ to allow direct comparison.

At the end of the $4^{\text {th }}$ day (the peak of parasite growth in vitro ${ }^{17}$ ), the contents of the tubes were observed using the Neubauer hemocytometer and the optical microscope. The results were compared with the numbers of parasites before treatment and expressed as percentages. This served to determine the lowest effective dose. Then, using this lowest effective dose, readings were taken from the $1^{\text {st }}$ to the $4^{\text {th }}$ day, using both the individual drugs and their combination. 


\section{Ethical considerations}

This research project was approved by the Ethics Committee for the Use of Animals (CEUA) of the Dante Pazzanese Institute of Cardiology, under the Project Registration No.: 008/2015.

\section{RESULTS}

The results are shown in Figure 1 and Figure 2.

\section{DISCUSSION}

This study was conducted to determine whether other drugs such as amiodarone have comparable in vitro trypanocidal action to BZ, the most widely used trypanocidal drug in Brazil. The efficiency of BZ treatment is unclear, and the literature is not consensual.

The analysis of randomized patients treated with either BZ or placebo (BENEFIT study ${ }^{19}$ ) showed that the drug was not effective in patients with established heart disease. Although BZ decreased the number of circulating parasites in blood, it did not significantly reduce clinical worsening. It was observed in this study that only one subset of patients, who had also been treated with amiodarone as well as BZ, seemed to benefit from the treatment ${ }^{19}$. A retrospective study evaluated patients with normal electrocardiograms, who were either treated with BZ or left untreated. After following these patients for two decades, a significant decrease was observed in the appearance of electrocardiographic changes in treated patients ${ }^{20}$.

Adesse et al. ${ }^{14}$ demonstrated that amiodarone induces drastic morphological changes in intracellular amastigotes in vitro, including mitochondrial swelling and disruption of reservosomes and the kinetoplast. The drug decreased intracellular amastigote count and trypomastigote release after completion of the intracellular parasite cycle, and blocked amastigote differentiation into trypomastigotes. It also promoted the recovery of cellular physiology concomitant with the elimination of intracellular parasites. Treatment with amiodarone of animals infected with $T$. cruzi reduced parasitaemia and increased survival. Although the antiparasitic activity of amiodarone has been shown before, there is a lack of data on the effect of this compound on T. cruzi structure and host cells, and the recovery of these cells after antiparasitic treatment. In the heart, the effects of this drug include inhibition of $\mathrm{Na}^{+} /$ $\mathrm{Ca}^{2+}$ channels. It was found that the in vitro and in vivo activity against $T$. cruzi take place through $\mathrm{Ca}^{2+}$ homeostasis disruption and inhibition of ergosterol biosynthesis ${ }^{14}$.

We cannot compare the drug concentrations studied here in culture with those observed in human plasma at the usual therapeutic doses, as the parasite concentrations are very different in both cases, and many factors interfere with the absorption of drugs.

Amiodarone treatment in mice infected with trypomastigotes has previously been seen to reduce parasitaemia and increase animal survival. When administered in combination with posaconazole, there was a delay in the progression of parasitaemia. Most of the animals treated with this combination presented a negative blood culture, xenodiagnosis, and blood polymerase chain reaction (PCR) for the nuclear deoxyribonucleic acid (DNA), indicating very low parasitic loads. These results demonstrate that amiodarone has anti-

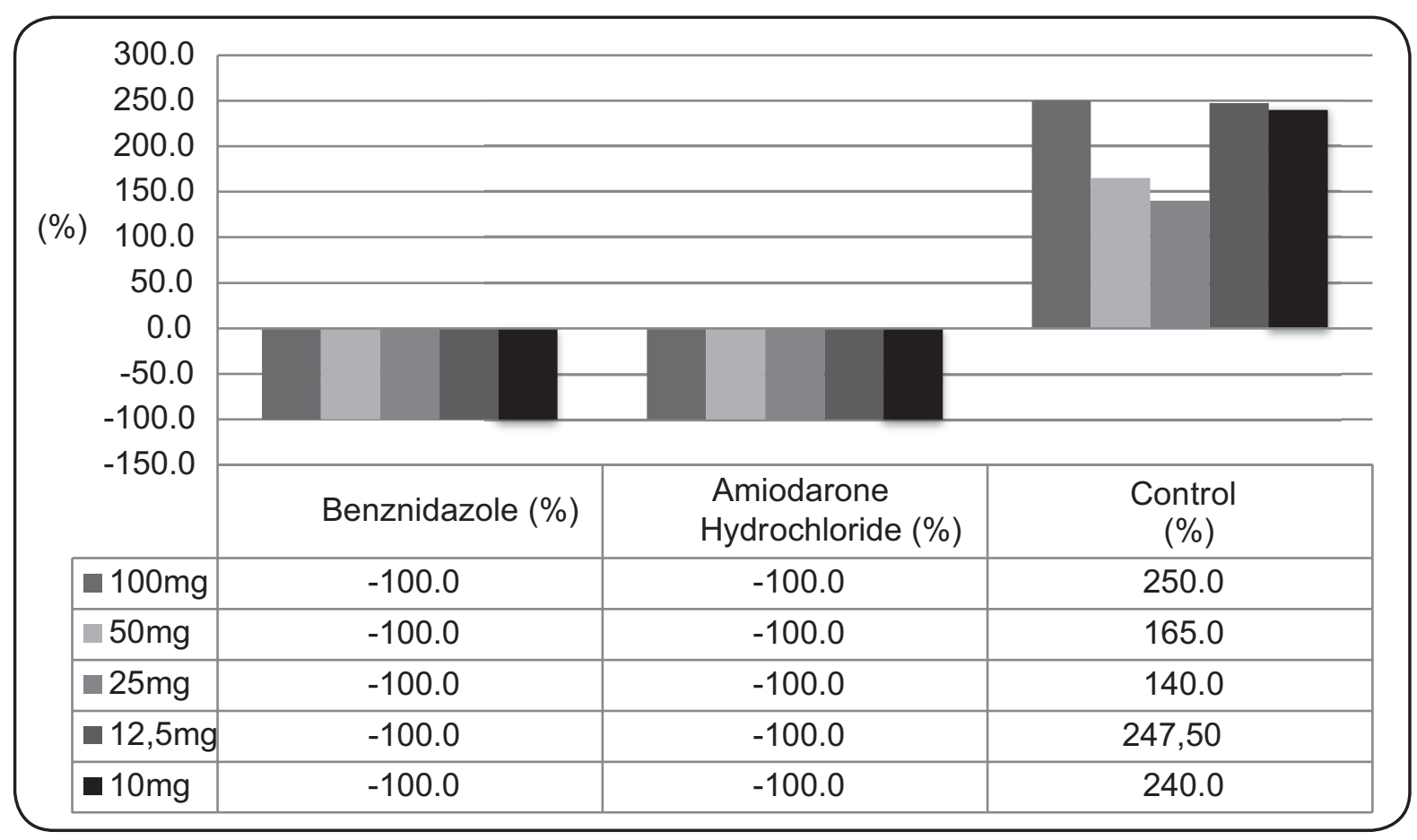

FIGURE 1: Variation in Trypanosoma cruzi in vitro culture cell count after treatment with different dosages of BZ and amiodarone, along with control culture counts. Readings were taken on the $4^{\text {th }}$ day after the addition of drugs. BZ: benznidazole. 


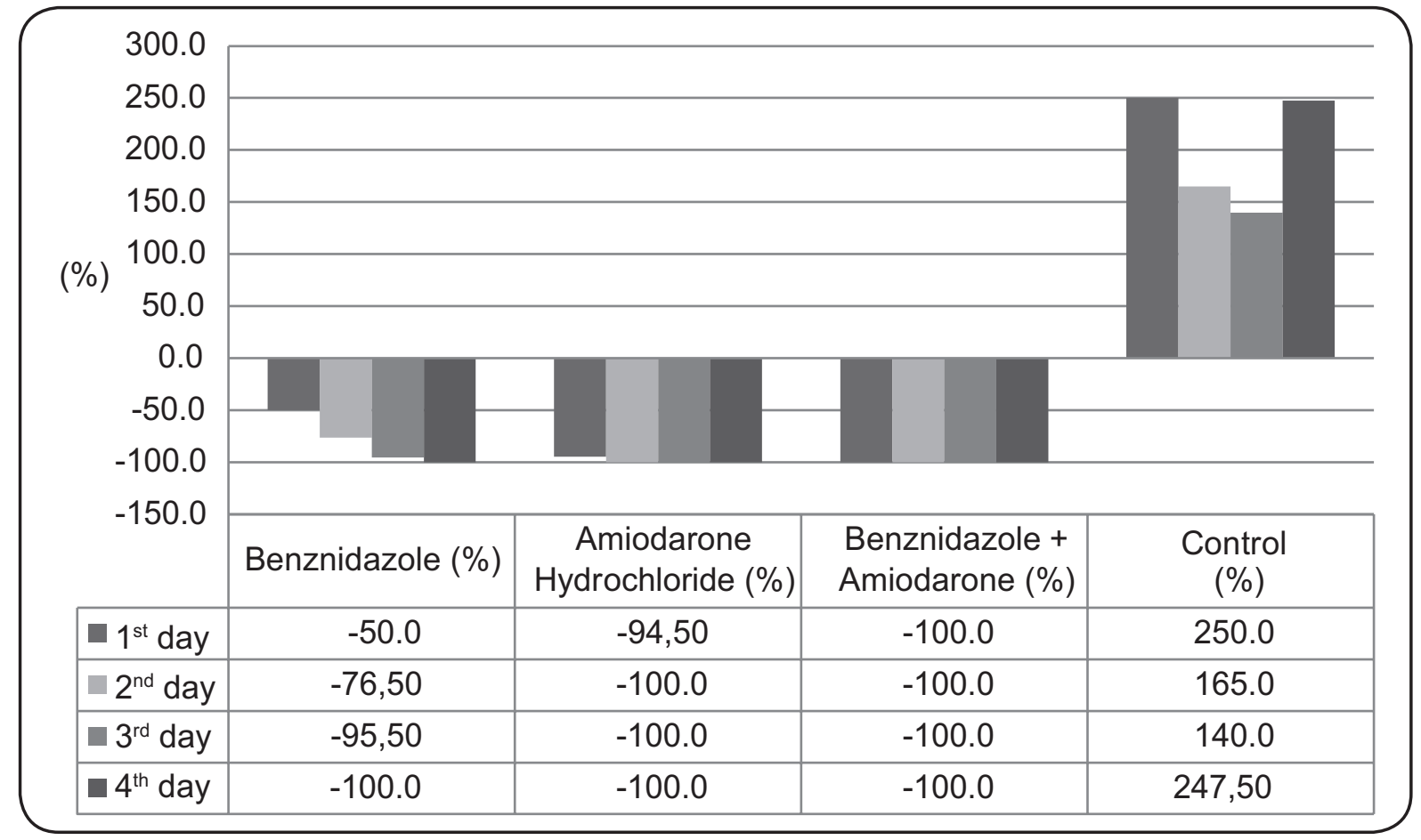

FIGURE 2: Variation in Trypanosoma cruzi in vitro culture cell count after treatment with $10 \mathrm{mg} \mathrm{BZ,10mg} \mathrm{amiodarone,} \mathrm{or} 10 \mathrm{mg}$ of both drugs in combination, along with control culture counts. Readings were taken from the $1^{\text {st }}$ to the $4^{\text {th }}$ day after the addition of drugs. BZ: benznidazole.

T. cruzi activity both in vivo and in vitro, used independently or in combination with other drugs ${ }^{12}$.

Oral transmission of Chagas disease is currently the most important route for T. cruzi transmission in Brazil, and can also be utilized by the epimastigote form of the parasite: in our cultures, almost all forms of $T$. cruzi were epimastigotes

We noted that in vitro, amiodarone had equivalent trypanocidal action to $\mathrm{BZ}$ at all doses studied; that is, all parasites ( $T$. cruzi epimastigotes) were dead on the $4^{\text {th }}$ day. When we added both drugs in combination to cultures, the same result was observed. It was therefore not possible to say whether these drugs had a synergistic effect, as there was no difference between the parasite counts in cultures treated with individual or combined medications on the $4^{\text {th }}$ day.

\section{Limitation of the study}

In this study, we used only the Y strain of T. cruzi, and were not aware whether amiodarone would have the same effect on other T. cruzi strains. We suggest that this study be repeated with the use of other T. cruzi strains, in order to determine whether the same results will again be obtained.

\section{Conflict of interest}

The authors declare that there is no conflict of interest.

\section{REFERENCES}

1. Chagas C. Nova tripanozomiase humana. Estudos sobre a morfolojia e o ciclo evolutivo do Schizotrypanum cruzi n.g., n.s.p., ajente etiolójico de nova entidade mórbida no homem. Mem Inst Oswaldo Cruz. 1909;1(2):159-218.

2. Dias JCP. História natural da doença de Chagas. Arq Bras Cardiol. 1995;65(4):359-66.

3. World Health Organization (WHO). Sustaining the drive to overcome the global impact of neglected tropical diseases. Second WHO report on neglected tropical diseases. World Health Organ. 2013. p. 57-59.

4. Mattos EC, Meira-Strejevitch CDS, Marciano MAM, Faccini CC, Lourenço AM, Pereira-Chioccola VL. Molecular detection of Trypanosoma cruzi in acai pulp and sugarcane juice. Acta Trop. 2017;176:311-15.

5. Dias JCP, Ramos Jr AN, Gontijo ED, Luquetti A, Shikanai-Yasuda MA, Coura JR, et al. II Consenso Brasileiro em Doença de Chagas, 2015. Epidemiol Serv Saude. 2016;25(esp):7-86.

6. Teixeira ARL, Gomes C, Lozzi SP, Hecht MM, Rosa AC, Monteiro PS, et al. Environment, interactions between T. cruzi and its host, and health. Cad Saude Publica. 2009;25(1):32-44.

7. Brener Z, Andrade ZA, Barral-Netto M. Trypanosoma cruzi e Doença de Chagas. $2^{\text {a }}$ edição. Rio de Janeiro: Guanabara Koogan; 2000. 431p.

8. Neves DP. Parasitologia Humana. 13a edição. Rio de Janeiro: Livraria Atheneu; 2016. 264p. 
9. Dias JCP, Coura JR. Clínica e terapêutica da doença de Chagas: uma abordagem prática para o clínico geral. $1^{\mathrm{a}}$ edição. Rio de Janeiro: Edição Fiocruz; 1997. 486p.

10. Fragata Filho AA. Tratamento etiológico da doença de Chagas. Rev Soc Cardiol Estado de São Paulo. 2009;19:2-5.

11. Muñoz RL, Fagúndes M, Klein S, Escanilla S, Torres G, Lee-Liu D, et al. Trypanosoma cruzi: In vitro effect of aspirin with nifurtimox and benznidazole. Exp Parasitol. 2010;124(2):167-71.

12. Benaim G, Sanders JM, Garcia-Marchán Y, Colina C, Lira R, Caldera AR, et al. Amiodarone has intrinsic anti-Trypanosoma cruzi activity and acts synergistically with posaconazole. J Med Chem. 2006;49(3):892-9.

13. Carmo AA, Rocha MO, Silva JL, Ianni BM, Fernandes F, Sabino EC, et al. Amiodarone and Trypanosoma cruzi parasitemia in patients with Chagas disease. Int J Cardiol; 2015;189:182-4.

14. Adesse D, Azzam EM, Meirelles MNL, Urbina JA, Garzoni LR. Amiodarone inhibits Trypanosoma cruzi infection and promotes cardiac cell recovery with gap junction and cytoskeleton reassembly in vitro. Antimicrob Agents Chemother. 2011;55(1):203-10.

15. Benaim G, Hernandez-Rodriguez V, Mujica-Gonzalez S, Plaza-Rojas L, Silva ML, Parra-Gimenez N, et al. In vitro anti-
Trypanosoma cruzi activity of dronedarone, a novel amiodarone derivative with an improved safety profile. Antimicrob Agents Chemother. 2012;56(7):3720-5.

16. Veiga-Santos P, Barrias ES, Santos JF, Moreira TLB, de Carvalho TM, Urbina JA, et al. Effects of amiodarone and posaconazole on the growth and ultrastructure of Trypanosoma cruzi. Int J Antimicrob Agents. 2012;40(1):61-7.

17. Camargo, EP. Growth and differentiation in Trypanosoma cruzi. I. Origin of metacyclic trypanosomes in liquid media. Rev Inst Med Trop Sao Paulo. 1964;6 (3):93-100.

18. Chiari E, Dias JCP, Lana M, Chiari CA. Hemocultures for the parasitological diagnosis of human chronic Chagas' disease. Rev Soc Bras Med Trop. 1989;22(1):19-23.

19. Morillo CA, Marin-Neto JA, Avezum A, Sosa-Estani S, Rassi Jr A, Rosas F, et al. Randomized trial of benznidazole for chronic chagas' cardiomyopathy. N Engl J Med. 2015;373:1295-306.

20. Fragata-Filho AA, França FF, Fragata CS, Lourenço AM, Faccini $\mathrm{CC}$, Costa CA. evaluation of parasiticide treatment with benznidazol in the electrocardiographic, clinical, and serological evolution of Chagas disease. PLoS Negl Trop Dis 2016;10(3):e0004508. 